\title{
A semantic differential for facial attribution: The face differential
}

\author{
DON HURWITZ, NANCY HIRSCHBERG WIGGINS, and LAWRENCE E. JONES \\ University of Illinois at Urbana-Champaigm, Champaign, Ilinois 61820
}

\begin{abstract}
Four groups of 10 subjects each (black males, black females, white males, and white females) associated a total of 2,400 personality descriptive adjectives to slides of 20 black and white male faces. Adjectives were grouped into synonym classes, and important adjective groups and their antonyms were selected on the basis of: (a) frequency of association; (b) judged relevance of adjective to faces; (c) judged commonness of opposite; and (d) judged commonness of adjective. This procedure was conducted for the whole group of 40 subjects by one investigator and for each of the four subgroups by another investigator. The two adjective lists were compared, and a final set of 27 bipolar adjective scales was selected as appropriate for the study of personality attributions to faces. Race and sex differences in the use of these adjectives were explored.
\end{abstract}

Because faces are meaningful social objects, they have come to play a prominent role as stimulus objects in such diverse areas as perception, social, and personality psychology (Cohen, 1973; Cross, Cross, \& Daly, 1971; Hochberg, 1964; Warr \& Knapper, 1968). Personality traits are readily attributed to facial photographs in an extremely consistent manner (Brunswik, 1956; Secord, 1958). Further, faces can be calibrated on the basis of verbal personality trait information, and this information is readily recoverable in the sense that subjects can "guess" correctly the verbal information conveyed by the face (Hochberg \& Galper, 1974). These phenomena, when combined with the fact that faces are also readily measurable on a variety of physical and cosmetic variables (Harmon, 1973), lead to the provocative possibility of generating a psychophysics of faces.

Unfortunately, previous studies involving trait attributions to facial photographs have lacked generalizability and comparability because of the difficulty of sampling systematically both faces and relevant personality attributions (Parrot \& Coleman, 1971; Parrot \& Saiia, 1972). The present investigation represents an initial attempt to calibrate and refine those personality characteristics, or attributes, which are salient, relevant, and important to facial perception, taking race and sex differences in to account. The general procedures employed in the present study were similar to the methodology used by Osgood and his associates (Osgood, Suci, \& Tannenbaum, 1957) in the early stages of the development of the semantic differential technique. In that technique, important adjectives were identified on the basis of free associations to various

The present research was supported by National Science Foundation Grant No. NSFGS 42801 to Jones and Wiggins. Reprint requests should be sent to Lawrence E. Jones. Department of Psichology. University of Illinois. Champaign. Illinois 61820. classes (nouns). In the present study, facial photographs constituted the concept class and the associations consisted of trait adjectives and phrases describing personality. The beauty of the elaborate procedure employed is in the guaranteed relevance of the adjectives associated to faces as well as in the production of anchors for scale construction which are grounded in the natural language of various known subject populations.

\section{METHOD}

\section{Subjects}

Ten black and 10 white male and 10 black and 10 white female subjects were recruited through fraternities and sororities at the University of Illinois. Each was paid $\$ 5$ for participating in a 2-h experimental session.

\section{Face Photographs}

The stimuli consisted of front-view facial photographs of college-age males in emotionally neutral poses. The photographs were originally collected by Malpass (Malpass \& Kravitz, 1969), using standardized lighting and photographic procedures. There were 10 white faces and 10 black faces. These faces were selected to represent variation along major dimensions of facial attribution identified in an earlier study (Wasserman, Wiggins, Jones, \& Itkin, 1974).

\section{Procedure}

The subjects were evenly divided into four groups on the basis of race and sex. Each group participated in one of four experimental sessions held on consecutive evenings, each procedurally identical with the others. Sessions were conducted by a black female and a white male, each acting as senior experimenter before his or her respective racial group.

Subjects were instructed to associate as many as three adjectives describing the personality of the person whose face was projected on a screen at the front of the room. The use of natural language was emphasized. Subjects were asked to act as if they would be describing to a friend the person whose face they were viewing. Two white and two black sample faces were used to familiarize the subjects with the task. Then, the 10 black and 10 white faces were presented in the same random order to the four subject groups. Each face was projected for approximately $2 \mathrm{~min}$. 


\section{RESULTS AND DISCUSSION}

The basic data consisted of three personality associations to each of 20 faces by 40 subjects. A black female worked with the whole group of approximately 2,400 adjectives, and a white male worked with each of the four subgroup's associated adjectives, separately. Each investigator grouped the words into synonymous clusters using, primarily, Roget's Thesaurus. Frequency counts of both number of words and number of different subjects contributing those words were made for each cluster of synonymous words. Major word clusters were then matched with their antonyms. To be counted as a major cluster, at least 15 subjects out of the total of 40 had to have used the words in the cluster; and at least 5 subjects out of the total of 10 had to have used the word for each subgroup of subjects. Where antonyms meeting the necessary criteria were not found in the Thesaurus, the prefix "un" or "not" was used. The major clusters and their antonyms identified in both analyses (the total group vs. the separate groups) provided the basis for the construction of bipolar scales.

The final determination of important adjectival scales was based on the criteria given by Osgood et al. (1957): (1) familiarity and frequency of usage of words in a cluster; (b) judged relevance of the words to faces; (c) commonness of opposite of words; and (d) judged nonambiguity of words. For each cluster of words, the most frequently associated word was chosen to represent the cluster, provided that word also satisfied all of the above criteria. For those word clusters requiring a judgment, the judges consisted of a male and a female psychologist and a male graduate student. The final set of 27 bipolar adjective scales selected for the investigation of attribution appears in Table 1.

A previous study by the present investigators, similar in conception to the present one (Wasserman et al., 1974), yielded some attribute scales not emerging in the present study. Those scales are also listed in Table 1 . It is noted that those scales were based on associations to face photographs by adult white male and female psychologists and, as such, may be of somewhat limited usefulness. Since the 27 scales based on the present data were contributed by black and white male and female subjects, they purportedly offer a higher degree of generality.

Although race and sex differences in word associations were not as marked as expected, a significance test of the difference between independent proportions did reveal some differences in frequency of word associations. Women associated the following adjectives more often than did men $(p<.05)$ : pleasant-unpleasant, warm-cold, and naive-sophisticated. Blacks, more than whites $(\mathrm{p}<.05)$, associated the scales honest-dishonest, conceited-not conceited, and, at the $\mathrm{p}<.01$ significance level, threatening-nonthreatening and cool-not cool.

The results of this study suggest a set of bipolar adjective scales, both relevant and salient, for facial
Table 1

Face Differential Scales

\begin{tabular}{lrlr}
\hline & College Age Subject Sample & \\
\hline 1. Intelligent & Unintelligent & 15. Alert & Sleepy \\
2. Naive & Sophisticated & 16. Sad & Happy \\
3. Dirty & Clean & 17. Sly & Not sly \\
4. Immature & Mature & 18. Cool & Not cool \\
5. Kind & Cruel & 19. Friendly & Hostile \\
6. Pleasant & Unpleasant & 20. Threatening Nonthreatening \\
7. Warm & Cold & 21. Conceited & Not conceited \\
8. Crazy & Sane & 22. Timid & Bold \\
9. Quiet & Loud & 23. Amusing & Unamusing \\
10. Strong & Weak & 24. Rural & Urban \\
11. Assured & Unassured & 25. Persistent & Not persistent \\
12. Calm & Nervous & 26. Dishonest & Honest \\
13. Afraid & Unafraid & 27. Sloppy & Neat \\
14. Hard & Soft & &
\end{tabular}

Adult Subject Sample (from Wasserman et al, 1974)

\begin{tabular}{lrcr}
\hline 1. Clean-cut & Greasy & 7. Masculine & Feminine \\
2. Likeable & Unlikeable & 8. Aggressive & Nonaggressive \\
3. Harmless & Dangerous & 9. Dark-skinned & Light-skinned \\
4. Attractive & Unattractive & 10. Talkative & Silent \\
5. Sexy & Unsexy & 11. Active & Passive \\
6. Bright & Dull & & \\
\hline
\end{tabular}

attributions. The procedures employed practically guarantee the content validity of these scales. It is presumed that further experimental and factor analytic work with the scales based on other face and subject populations would establish their reliability, generalizability, and construct validity.

\section{REFERENCES}

BRUNSwIK, E. Perception and the representative design of psychological experiments. Berkeley: University of California Press, 1956.

COHEN. R. Patterns of personality judgment. New York: Academic Press. 1973.

Cross, J. F.. Cross, J., \& Daly, J. Sex, race, age. beauty factors in recognition of faces. Perception \& Psychophysics, 1971, 10, 393-396.

HARMon. J. D. The recognition of faces. Scientific American, 1973. 229. 70.83 .

Hochberg. J. E. Perception. Englewood Cliffs: Prentice-Hall. 1964.

HochbeRG. J.. \& GALPER, R. Attribution of intention as a function of physiognomy. Memory \& Cognition. 1974, 2. 39-42.

MALPASS. R. S. \& K Kavitz. J. Recognition for faces of own color and other "Race." Journal of Personality and Social Psychology". 1969. 13. 393-396.

Osgood. C. E.. Suci, G. J.. \& Tannenbaum, P. H. The measurement of meaning. Urbana: University of Illinois Press. 1957.

Parrot. G. L.. \& Coleman. G. Sexual appeal: In black and white. Proceedings of the 79th Annual Convention of the American Psychological Association. 1971. 6. 321-322.

Parrot. G. L.. \& SaIIA. S. Heterosexual perception: In black and white. American Psychological Association Proceedings. 80th Convention. 1972. 289-290.

SECORD. P. F. Facial features and inference processes in interpersonal perception. In $R$. Taguiri \& $L$. Petrullo (Eds.), Person perception and interpersonal behavior. 1958. 300-315. 
W ARR. P. B.. \& KNAPPER. C. The perception of people and events New York: Wilev. 1968.

Wasserman. J.. Wiggins. N.. Jones, L., \& Itkin, S. A cross cultural study of the attribution of personological characteristics as a function of facial perception. New Orleans: American Psychological Association Proceedings. 1974.

(Received for publication Julỵ 2. 1975.) 